\title{
DRG benennt wichtige Auszeichnung für Radiologen nach Marie Curie
}

Der zum 50. Geburtstag der Deutschen Röntgengesellschaft gestiftete HermannHolthusen-Ring, der von 2010 bis 2014 Wilhelm-Conrad-Röntgen-Ring hieß, bekommt einen neuen Namen: Ab 2015 wird die Auszeichnung nach der bedeutenden Atomphysikerin und Radiologin Marie Curie benannt. Die in Polen geborene und in Frankreich berühmt gewordene Nobelpreisträgerin (1867-1934) hat die Physik, Chemie und Radiologie gleichermaßen immens beeinflusst, insbesondere durch die gemeinsam mit ihrem Mann Pierre Curie entdeckten Elemente Radium und Polonium sowie ihre Studien zur Radioaktivität.

Der Ring zeichnet einen herausragenden jungen Wissenschaftler der Radiologie aus, wobei die Kandidaten/innen hierfür vorgeschlagen werden müssen. Grundlage der Begutachtung sind die gesamten bisherigen Leistungen, die im besonderen Maße befähigen sollen, eine herausragende wissenschaftliche Laufbahn zu vollenden.

Mit der seit 2015 erfolgten Umbenennung der Auszeichnung in Marie-Curie-Ring wird diese Perspektive beispielhaft hervorgehoben. Die Preisverleihung findet jährlich auf dem Deutschen Röntgenkongress statt. Eine Jury entscheidet über die Preisvergabe.

Das wichtigste Kriterium für die Auszeichnung sind die wissenschaftliche Re- putation und Kompetenzen, die sich die Kandidaten im Rahmen von Veröffentlichungen und Vorträgen im nationalen und internationalen Rahmen erworben haben. Die Preisträger sollten in der Regel nicht älter als 40 Jahre sein und werden vorgeschlagen.

Einreichungsfrist für den Marie-CurieRing 2015 ist der 28. Februar 2015. Alle Informationen auf www.drg.de > Über uns $>$ Preise und Auszeichnungen $>$ MarieCurie-Ring. Ein ausführliches Portrait zur Person von Marie Curie finden Sie dort ebenfalls in Kürze.

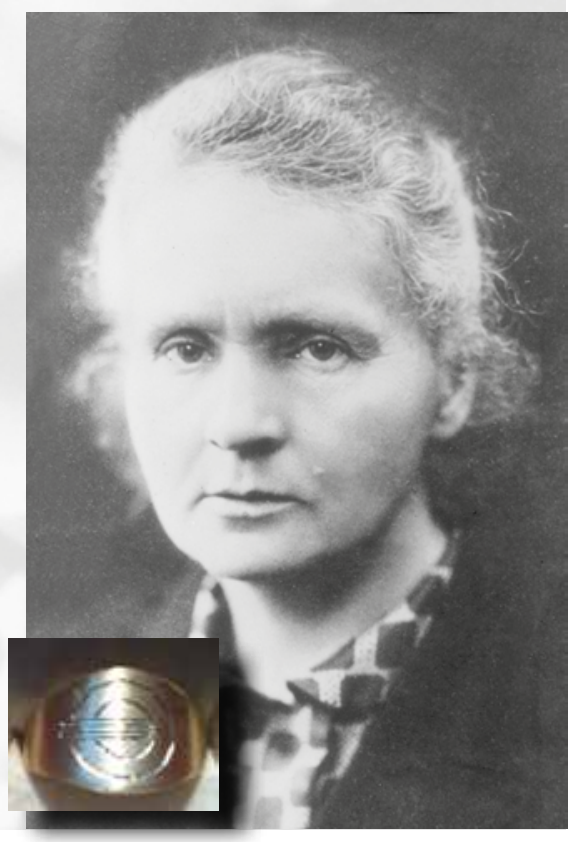

